\title{
Chapter 13 \\ Conclusions: Participating as Power? \\ The Possibilities and Politics \\ of Participation
}

\author{
Céline Cantat
}

The three texts featuring in this section of the volume have been brought together by the editors because they engage in a range of ways with the issue of participation in the production and distribution of knowledge on migration, including visual ethnographic and artistic material. It is worth noting already at this point that the focuses and actors of the participatory methods discussed in the three texts can hardly be accounted for by a generic reference to migrants and migration. In Stefano Piemontese's text, the author encourages the active engagement of Romanian "Roma" youth in data collection, by inviting teenage research participants to conduct interviews with him, and to produce their own audiovisual accounts of their social world. The fieldwork takes place across a range of contexts - between Spain and Romania, urban life and rural communities - and involves multiple more or less successful attempts at moving away from traditional ethnographic methods and carving space for more experimental endeavours. The short videos that Piemontese's "co-researchers" shot are sometimes documenting their environment and sometimes based on fictional scripts written in advance - in ways that resemble the "ethno-fictions" Jean Rouch speaks about. Piemontese reflects on this process both from the perspective of how data is collected as well as with regards to evolving relations in the field, and the ethical and personal dilemmas they raise.

Karolína Augustová, in her investigation of irregularised mobilities in southeast Europe, mobilises photographic methods in order to explore the "hidden and securitised" spaces of violence that characterise the experience of young men attempting to cross dangerous borders in the hope of reaching western and northern Europe. Border-crossers with whom she works are involved in photo-taking, as a way to provide visual representation of their journey from their own perspective. What results is a visual documentation of the range of power devices deployed to govern and repel these young men in their attempted mobilities, which particularly

\footnotetext{
C. Cantat $(\bowtie)$

Centre de recherches internationales (CERI), Sciences Po, Paris, France
} 
evidences the brutality of borders and their effects on the bodies of research participants. Photo-elicitation is in turn used to reconstitute complex narratives and emotions, and to explore research participants' interpretative frameworks in less constrained ways than a codified interview would allow.

Finally, Lucie Bacon, Amandine Desille and Noémie Paté's text reflects on the authors' attempt at imagining more collective and inclusive forms of disseminating academic, artistic and activist outputs concerned with migration. Here, the emphasis of participation shifts. Its subjects are not primarily the mobile people about whose experience research or artistic projects were conducted, but rather the various communities of authors engaged in producing alternative representation around migration and which usually operate autonomously. Based on the experience of organising an event attempting to bring together members of these various scenes, the text ponders the possibility and limitations of creating platforms about international migration that operate across and beyond the boundaries that usually compartmentalise these different forms of knowledge production.

Yet, beyond the diversity in contexts and protagonists of these three texts, a number of shared concerns can be identified. On the one hand, like other texts in the volume, these contributions raise important methodological, deontological, epistemological and conceptual issues regarding (visual) knowledge production, the ethics of fieldwork and the politics of representation in migration research. On the other hand, based on their empirical experience of conducting and disseminating participatory research, the texts assess these questions with specific regards to participation, and thus propose insights into what meaningful participatory processes are, and what they can contribute in particular to social science projects about migration.

As a result, the whole spectrum of research practices is put, directly or indirectly, to the "test of participation" and a range of sometimes uncomfortable questions emerge: does meaningful participation require that researcher and researched conceptualise the research plan together before its start? What are the tools and methods available to enable participation at different stages of the research process, and what are the potential limitations and tensions that such endeavours meet? Are visual practices particularly conducive to participation? Can the co-production of knowledge, particularly but not solely in a visual form, ever be a horizontal and equal endeavour? Can participatory methods ensure a form of relevance to participants' own realities and rationales, and how do those stand in relation to the hegemonic idioms and norms of academia as an institution? Does participation per se guarantee an ethical stance? What is the responsibility of the researcher in terms of political and epistemological self-reflection when she encourages participation in her research?

In this commentary, I will reflect on how these questions are addressed in the three texts and on what this implies in a broader way for social sciences that aim at producing knowledge around migration that is meaningful in today's world. I first offer further reflections on dominant regimes of representations of migrants and on the consolidation of a visual knowledge-power nexus around migration. Against this background, I move on to consider how the three texts' mobilisation of 
participation enables the production of counter-hegemonic accounts and knowledges of migration experiences. I then focus in particular on the issue of violence and migration, and assess the ways in which participatory methods can challenge the displacement of violence that underpins dominant and exclusionary representations of migration. The next point turns to processes of collective knowledge distribution and explores the possibilities opened up by thinking dissemination as a participatory process. The text finally concludes on a reflection on participation as a relation that is always under construction, and which while tending towards equality remains contested and unstable.

\subsection{The Intersecting Economies of Migrants' Representation}

The texts' focus on migration locates them within a discursive, interpretative and visual field that is increasingly characterised by a generic and negative representation of mobile people. In Europe, as in much of the Global North, this has been mirrored by exclusionary, exploitative and sometimes murderous policies and practices towards people on the move. Within this overarching frame of the generic "migrant" as always potentially threatening, the particular social groups researched in each text are also each embedded into specific symbolic and moral economies. The young people involved in Piemontese's research, as young "Roma" Romanians circulating between Romania and Spain find themselves at the intersection of at least three depictive systems: one concerned with eastern mobilities towards western Europe, one drawing on a long history of anti-Roma images and sentiments, and finally one focused on "youth gangs" as "barbaric" (Piemontese, Chap. 10, this volume). Each comes to reinforce the other towards the normalisation of discrimination.

Augustová's research participants ("17 men from Afghanistan, Pakistan and Syria, between 17 and 28 years old" living in a state-run camp) are similarly locked within a hegemonic regime of representation associated with threat, crisis and illegality. The hyper-visibilisation of borders and migration as part of what De Genova (2013) has famously coined "the border spectacle" sets the scene for a narrative of exclusion and state protection against those depicted as unwelcome outsiders. As such images come to saturate public and media discourses around migration, the space for alternative representations shrinks. In particular, the legal and physical violence exercised over the bodies of border-crossers becomes invisibilised within the grand narrative of "illegal migrants" attempting to undermine the state's territorial integrity. At the other end of the spectrum of truth regimes about illegalised travellers, the dehumanisation of camp residents as passive and ahistorical objects of humanitarian intervention, lacking agency and determination, is also a pervasive trope (Maalki, 1996). 
Such images equally underlie the "hostile and inhospitable environment' which Bacon, Desille and Paté grapple with as they try to organise an event proposing different accounts and representations of migratory experiences. In their case, the challenge appears as both a series of questions regarding the possibility and challenges associated with deconstructing such hegemonic and dehumanising images of "migrants", but also as a series of practical and organisational obstacles as, for instance, their fundraising efforts are met with "suspicion" due to the focus of their event (Bacon, Desille and Paté, Chap. 12, this volume).

\subsection{Visuality and Domination}

Relocating these texts into the broader economy of representation that has consolidated around migration - as well as into the specific systems of truth around each particular group in the studies - is important. In Europe, hegemonic knowledge about "migrants" is based on long histories of unequal relations between Europe and its outsides, which have been sustained by particular regimes of representations. In this context, certain narratives about "migrants" and migration occupy such an authoritative space in contemporary European discourses, that it has become extremely difficult to speak about migration outside references to them. Increasingly, migration as a subject of thought, action or representation feels limited and determined by this large network of dominant discourses and images. Hegemonic depictions of migration have also sustained and justified exploitative, neglectful and violent practices towards "migrants". This articulation between knowledge and power is key when conceptualising research about migration and the possibilities and challenges raised by "participation".

The relation between knowledge and power has been widely explored, leading to concepts such as that of ideology in the Marxist literature, hegemony in Gramscian interpretations and to discursive theories of power in more recent critical cultural studies analyses where emphasis on race and gender is added to reflections on class positions (see Hall, 1992; Stoddart, 2007). Of particular relevance here, is Edward Said's seminal work on "Orientalism" - a term he coins to depict a way of knowing which produces, emphasises and stabilises particular sets of representations of the "Orient" (Said, 1978). Orientalism is a form of knowledge based on an "ontological and epistemological distinction" (p. 2) between a European "we" (modern and progressive) and an oriental "them" (backward, uncivilised and potentially dangerous). This "knowledge" relies on a series of representations which propel into existence both the "Orient" and the "West", whose very existence, raison d'être and boundaries emerge in relation to each other.

Hence, very importantly, while Orientalism is a discursive and epistemological construction, it soon becomes a device of power, a tool of domination, which both justifies and in fact demands European imperialist interventions in the "East". As such, the discourse of Orientalism, Said contends, was essential to the way European culture "was able to manage and even produce the Orient, politically, sociologically, 
militarily, ideologically, scientifically and imaginatively" (p. 3). Today, the structural marginalisation of particular groups including migrants is similarly justified in the name of "insurmountable cultural and civilisational differences', which are produced and reproduced through particular discourses and images (Cantat, 2016, p.58).

The specifically visual aspect of the power-knowledge nexus has also received attention, for instance with Deleuze's exploration of the importance of visuality in Foucault's thought and the necessary connection between "seeing" and "controlling" (Deleuze, 1986), in studies of visual cultures (Mirzoeff, 2008, 2011), and in analyses of the relation between systems of domination and visual artefacts (see Chaudhary (2012) for an analysis of photography and colonialism or Landau and Kaspin (2002) for an exploration of imperial visuality). These studies have greatly contributed to de-naturalising visual products by moving away from claims that they are "neutral" and accurate mediums, merely objectively copying reality. Rather, critical approaches suggest that we look at the active process of selection and interpretation through which a visual object is produced, and that we assess its meaning in relation to situated material circumstances and social relations (Hall, 1992). As per the striking introduction of John Berger's Ways of Seeing, "[t]he relation between what we see and what we know is never settled" $(1972$, p. 7). Photographs need language: they make and are given sense within broader (political) narratives. What Berger powerfully shows is that "seeing" is a situated act, and a historically constructed process. When and where we "see" something will impact on what we see and how we interpret it.

The social context of photographs is also evocatively highlighted by Yannick Le Boulicaut, when he states that "there is no such thing as a candid shot" (2013, p. 22). In his work on colonial and postcolonial photographs, Le Boulicaut (2013) observes that visual choices are active and multiple. They concern what or whom to show, how to show, from which angle and perspective, with which lens, following which composition - among other things. In this sense, if they are aesthetic and technical, they are also social and epistemological. These choices emerge from and are made possible by power relations - between the photographer and photographed as such, but also between the social groups to which each belongs. Ultimately, in his study, Le Boulicaut shows that contemporary photography still tends to respond to a visual grammar deeply embedded into a Eurocentric worldview. In other words, while also being governed by distinct norms, images (including moving images) do not operate autonomously from their social context. They are produced and seen within broader moral, symbolic, aesthetical and political economies - which shape them and which they in turn shape.

The fact that visual forms can be the expression of - and can sustain - relations of domination is acutely perceived by the people Augustová comes across as she conducts fieldwork. She reflects on the camera as a "predatory object" "of exploitation and aggression", and on the fact that it can make those it is pointed at feel "undermined, exploited and attacked" (Augustová, Chap. 11, this volume). The relation between being seen and being controlled evoked earlier is critical, as these men are subjected to systems of surveillance aimed at exercising authority over their activities and movements. Attempts at filming or photographing people trigger 
anger, which evidences their refusal to be submitted to situations of objectification or animalisation ("this is not a zoo!"). Essentially, what is being denounced here are the social relations premised on the erasure of people's agency and right to selfrepresentation that allow for objectifying and animalising images to be produced by external photographers. This testifies to the power of visuality - including as a tool of control and domination.

\subsection{Visual Participation and Counter-Hegemony}

When can visuality, then, subvert domination? In all three texts, the deconstruction and contestation of hegemonic representations about "migrants" are important objectives which visual practices are seen as advancing. Moreover, in this context, participatory practices are presented as a necessary step towards more radical epistemological reflexivity. In more or less explicit ways, the three chapters thus present participation as a tool and a process seen as holding the potential to challenge dominant regimes of discursive and visual truths.

Primarily, participation emerges as a different form of social relation per se, which challenges modes of interpellation of migrants based on extreme forms of exclusion and dehumanisation. Relatedly, participation shifts away from a positivist approach to knowledge production based on particular assumptions regarding the relationship between researcher and researched - one where knowledge about migrants is produced exclusively by researchers. This epistemology of knowledge production is reminiscent of Said's remarks about how the West produced the Orient. Commenting on how a Western writer produces the "Oriental woman", he comments that "she never spoke of herself, she never represented her emotions, presence, or history. He spoke for and represented her" (Said, 1978, p. 14). If participation means, as it is argued in the texts, the collaborative inclusion of alternative perspectives and viewpoints in the production and dissemination of knowledges around migration, it is in itself potentially subversive. Epistemologically, the reversal of gaze that is operated when the recording device (be it a pen, a recorder or a camera) is handed over to those the research studies, and the deconstruction of the pretension to objectivity and comprehensiveness of researcher-led accounts, are already counter-hegemonic gestures.

Still, participation bears questions: a set of issues arises regarding the nature of the relations that allow, or that may count as, "authentic" (non-constrained, nontokenistic) participation - and I will come back to those later in the text. Another range of concerns focuses on the knowledge "output" of participatory research. Does a methodological process featuring such "counter-hegemonic gestures" suffice to produce counter-hegemonic knowledge? Or perhaps more precisely: under which specific conditions could the counter-hegemonic epistemological potential of participation emerge? Piemontese importantly notes that self-representation, while expected to subvert dominant discourses about discriminated groups, does not automatically produce alternative representations because of the power of 
internalised stigmas and the dominance of a specific visual grammar as described above. In his text, participation in the form of asking research participants to produce representations of themselves unmediated by the ethnographer, does not seem to bear fruit in terms of producing counter-narratives.

This seems indeed a corollary of cultural hegemony: it is precisely because it takes hold over those presented as superiors and those deemed inferiors that it amounts to hegemony. As a system of knowledge with a pretension to comprehensiveness, embedded in dominant visual grammars and norms, it renders the possibility of articulating different views extremely difficult. Yet, in Piemontese's text, when at a later stage in his research, and following the careful crafting of relationships of trust and collaboration, participants start sending him videos of their everyday life, something seems to have changed. Piemontese explains that he finally sees "their world through their eyes". At this later stage, participatory methods thus do manage to offer a viewpoint not yet accessed by the researcher, which complexifies and deconstructs some of the images he had hitherto built of the social world of participants. Participation does, then, expend ethnography into a dialogical and polyphonic process that allows transcending the authoritative voice and presence of the ethnographer and making space for what Boaventura de Sousa Santos (2008) has called "epistemological diversity".

In my view, an important point coming from Piemontese's account is that meaningful participation - one that allows the emergence of alternative narratives - is deeply connected to the social relations and forms of communication that underpin the research process. Participation in a non-perfunctory fashion seems to emerge in Piemontese's work as the source but also the product of dialogical practices of reciprocal explanation and elucidation. It needs time and construction: it is not a given. It is only under such conditions that a shift away from the mystical "sublimed gaze" of the researcher, and towards the recognition of the partiality and incompleteness of any account, can open up a space for counter-discourses and countervisualities to emerge. What the text does not reflect on further, is the gesture through which the meanings accessed through the videos shot by participants are in turn integrated into the research after data collection and in the production of scientific outputs, be they textual or visual.

\subsection{Participation and the Re-placement of Violence}

The possibilities offered by participatory methods regarding the production of counter-hegemonic knowledges are also striking in the research undertaken by Augustová. In this case, participation helps circumvent the legal and institutional constraints within which research protagonists exist, as camp residents and illegalised travellers, and within which the ethnographer has to operate. These restrictions prevent "migrants" speaking in their own terms and researchers (but also journalists, photographers, and the broader public) from accessing certain spaces and temporalities - and contribute to keeping practices and sites of violence 
remote, obscure and out of the public and ethnographic eye. Photo-taking comes as a means for the articulation of a different discourse based on migrants' testimonies. Here the authoritative voice of visuality plays in the favour of migrants who are able to document and thus testify to the violence they encounter in various hidden spaces.

Self-narration (visual and speech-based) of the coercion experienced by illegalised travellers reveals the displacement of violence that animates dominant discourses around migration in Europe, such as rhetoric of a migration crisis and of migrant illegality. In dominant representations, it is indeed Europe - its "culture" and "way of life", its democracy and politics - that is narrated as being in crisis or under threat (Rajaram, 2016, p. 5). In this sense, dominant discourses are not only exclusionary, they are also premised on an inversion of roles between perpetrators and victims that requires an obscuring both of the social and political histories that participate in people's displacement and of the brutality experienced by migrants at Europe's multiple internal and external borders. As per Said's earlier comment, they demand that people be "spoken for". A systematic silencing of displaced people is required in order for the hegemonic epistemology presenting Europe as a space of virtue, prosperity and safety put at risk by its threatening and unruly outsides to prevail.

Participation through photo-elicitation allows exploring the meaning of these spaces for those who pass through them from a perspective that is not predetermined by the researcher's own understanding. For instance, it reveals the experiential continuum between different loci of Augustová's participants' everyday life. The insalubrious camps in which they are forced to wait, and which are so often represented in dominant narratives as humanitarian spaces of passivity and inactivity, emerge as the antechambers of broader border-crossing projects. They appear as sites of intensive organising, information sharing, collective support and mutual care - all aspects that may go unnoticed, even by a careful ethnographer, due in particular to the many restrictions imposed on her presence in the field.

Importantly, therefore, beyond capturing a series of "experiences", participatory visual methods also evidence modes of organising enacted by illegalised migrants which point to communities and subjectivities that are actively ignored and obscured in dominant accounts. As I explore in my own work on migration solidarity, such practices and sites challenge the dominant political architecture that centres on the nation-state and presumes that the sole subject of political action is the citizen. In such accounts, displaced people tend to be seen as all together outside of the realm of the political and are locked into their representation as objects of suspicion, in security-oriented approaches, and of compassion in humanitarian responses. As evoked, these are problematic and depoliticising representations, which invisibilise the political reasons that produce displacement in the first place, and deny people's capacity to become autonomous political subjects who act in defence of their interests and those of others in their new countries of transit or residence.

Participatory research, as a means of re-centring accounts of migration around the violence experienced by travellers but also around the active agency they deploy to organise towards various goals (linked to mobility or not), thus allows counterhegemonic accounts. This is not to say that participation is the only possible way to 
do so, and many critical academics, activists and journalists have both denounced Europe's border violence and insisted of the political subjectivities of people on the move. But, here, participatory visual research offers space for victims of abuse to articulate and narrate their experiences in their own and particular terms - including non-textual ways - while simultaneously pointing to emergent political subjectivities and communities that dominant accounts insist on denying.

\subsection{Collaborative Knowledge Distribution}

Participation as a counter-hegemonic tool is explored in a slightly different way in the text by Bacon, Desille and Paté. The key ambition of the described endeavour is to produce a hybrid (scientific, artistic and activist) event, in order to reach broader publics and to construct a community of praxis and knowledge that borrows from different ontologies. By decompartmentalising these different modes of engaging with migration, the authors seek to reflect on and deconstruct some of the disciplinary and institutional constraints within which researchers, artists and activists work. This is also, therefore, an initiative that starts from a recognition that knowledge is partial. It is premised on the belief that the integration of perspectives and ways of thinking from various modes of meaning-production can create alternative outcomes that subvert established "ways of seeing" (Berger, 1972).

What is also of particular interest in this text is the idea that knowledge distribution - as much as its production - can be thought of in a more open, democratic way. This requires partly moving away from the traditional forms of scholarly publications that are usually acceptable to the academic community and, importantly, required for the career advancement of scholars such as the authors of this piece. As such, investing efforts, time and resources in crafting an event that subverts the dominant norms of knowledge propositions in academia is a courageous move that resists the constantly growing pressure for the commodification of all forms of knowledge. Here, participatory and collaborative methods seem to be mobilised towards the advancement of what Lonnie Rowell and Allan Feldman (2019) have called "knowledge democracy". Knowledge democracy, they claim, is based on the intersection of three processes: "acceptance of multiple epistemologies, affirmation that knowledge is created and represented in multiple forms (...) and understanding that knowledge is a tool ... to create a more socially just and healthy world" (Rowell \& Feldman, 2019, p. 2; Hall \& Tandon, 2015). While these three phenomena are of interest to all the authors, the emphasis in this text is put on the last two aspects unlike perhaps Piemontese's and Augustová's which are primary concerned with the recognition and inclusion of diverse perspectives.

Based on this definition, breaking boundaries between science and arts, and across disciplines, is a condition to further democratise knowledge. It allows recognising that there exist multiple non-textual ways in which knowledge about the world can be accessed and rendered. It also connects knowing with senses and emotions, in a way that traditional academia would usually occlude in the name of 
scientific objectivity. Bacon, Desille and Paté refer to this possibility as an "embodied experience" that is made possible through artistic practices. This opens an avenue for important research questions where the study of the connection between migration and emotions could potentially move away from a purely pathological take - that is, from a view that only considers how negative or traumatic experiences encountered in migratory processes lead to difficult emotions conducive to particular (mental and physical) health issues. While this is of course an important issue, as the sole angle through which emotions are approached in migration contexts, it risks reproducing dominant representations where people are seen as either passive victims of their presumed circumstances, or executors of fantasised emotionalcultural norms of "origin countries" (Albrecht, 2016). A more sociological approach to emotions and migration could perhaps provide further insight on the role, functions and constraints of emotions in contexts of migration (ibid.). In this emerging field of inquiry, it seems that participatory artistic practices giving space to the affective aspects of migration are crucial to further our understanding of the emotional duress of migration and the process through which individuals establish themselves as the creators and narrators of their experiences.

As far as Bacon, Desille and Paté's event is concerned, the authors explain that the process of coming-together has contributed to the emergence of a "reflexive" community, where the shared goal of presenting alternatives to dominant representations of migration has been reinforced and enlarged. They also note that the constraints and pitfalls of this endeavour are numerous and that the establishment of collective subjectivities based on solidarity is a challenging task, particularly considering the material conditions of the academic, artistic and activist sectors. A point that might have deserved further examination is the limited presence of the protagonists of the migratory journeys - "migrants" - at the event. The authors evoke their restrained mobility as a key reason for this absence, which certainly constitutes a frequent and deplorable obstacle. Yet it could also have been interesting to enlarge the reflection to assess its meaning in terms of who can participate in the production and the distribution of knowledge and what are the implication regarding epistemology, biases and monophony. This tension in fact leads to the final set of questions I will address, which are concerned with participation and power relations in the field and question whether participation can ever claim full horizontality.

\subsection{Participation as Equality?}

If participation relies on social relations, which hold the potential to disrupt dominant modes of knowledge production and distribution, a number of important questions must be addressed: what counts as participation in each particular context? What kind of social relations are conducive to participation? What socialities, between researcher and participants but perhaps also among participants, are displaced or emerge in participatory contexts? What particular responsibilities or ethical duties may participation demand? Is participation enough to contest cultural 
hegemonies beyond the site of the fieldwork? And if participation is extended in an effort to challenge power relations, do others power imbalances risk emerging in participatory contexts?

All three texts are concerned with the nature and negotiation of the relation of collaboration that their authors develop with those participating in their projects. Piemontese struggles with compensating for "unequal power relations" between him and his interlocutors - arguably, this concerns both the hierarchy between researcher and researched, as well as the different classed and racial positionings which they occupy within the broader social order. Indeed, the possibility of cultural hegemony evoked previously does not emerge outside of the larger social context and its symbolic and material economies. Augustová reflects on "power positionalities" and states that she does "not want to be associated with exploitative and merely Euro-centred visual conceptualisation". She partly links this Eurocentrism to institutional demands of the media or academia, reproducing mainstream understandings of how to document illegalised travellers. This leads for instance to photographers acting without "consent or empathy". She denounces extractive relations when journalists or academics appear on the field only to capture preconceived images of displaced people, then immediately disappear. How can the researcher navigate such constraints in order to produce conditions that are truly conducive to participatory relations? For Bacon, Desille and Paté, the key challenges are the "hierarchies between partners", the speed at which the norms and boundaries from the different disciplines represented in their event can come up again against each other, and the risk that collaboration without serious consideration for people's material conditions may reproduce exploitation.

In other words, participation while allowing for an epistemological diversity that is a crucial first step towards deconstructing hegemonic modes of representation is not a short-cut for equality or horizontality. While the language of participation and diversity is powerful, it cannot per se mitigate the social hierarchies between participants that exist outside the "field" and also come to constitute it. Piemontese in particular explains in detail how he attempted to deal with economic imbalances in his relations with participants, by agreeing on a renumeration for their involvement and work towards his research project. To an extent, this also provided a solution to some of the ethical questions he had been grappling with, concerned with the different purpose and interest the research held for the teenage participants. It also acts as a means of empowering participants, by recognising the value of their contribution, and thus a means to deepen "authentic" participation.

Beyond this material aspect, an interesting element of Piemontese's reconstitution of his research process is the way in which the meaning of participation seems to change as relationships are built and develop among the participatory group. On the one hand, as trust and mutual understanding are constructed between the researcher and participants, participatory relations seem more possible. On the other hand, it seems that participation requires that all those involved understand, appropriate and value the purpose and logic of the research process and project. Indeed, participation seems conditional on how relevant the research is to the researched, and to their own understanding of what their social needs and 
issues are. This perhaps implies that radical participation towards counter-hegemonic objectives requires (or is greatly facilitated by) the early involvement of those the research studies in the very formulation of questions, hypotheses and objectives.

\subsection{Conclusion: Theorising Participation}

Here more theorisation of research participation might be required - one that recognises its contested nature and politics. Such a reflexive and critical stance on participatory methods has emerged in development studies, in response to the normalisation of "participatory development" (Hickey \& Mohan, 2005). Among other critiques, Cornwall speaks of participation as an "infinitely malleable term" (2006, p. 50), which has been applied to a wide range of situation and for an infinite number of purposes. While important pieces such as those in this section have been written on empirical experiences of participatory research, a broader theory of participation is perhaps still missing. This might be connected to neoliberal academia's growing need to identify a clear authorial voice that can be credited and referenced, and whose relevance and competitivity can be quantified through scientific rankings and indexes. While participation is indeed becoming more common in scientific research, it remains curiously under-conceptualised.

It would be of interest, in particular, to assess the distinction between "participation from above" - as an increasingly fashionable methodological approach that can easily slip into tokenism - and "participation from below" as a powerful demand made by communities for being included in studies that concern them. In most actual research processes, logics of participation from above and below will likely interact and the researcher, herself acting under various constraints, will have to navigate the resulting tensions.

In any case, the reflections brought together in this text perhaps indicate that participation cannot be only assessed as a process or a set of relations, nor can it be only accounted through more conceptual analyses of knowledge and power. Participation in a radical sense is about allowing people to set the agenda and to thus place certain demands on it. A holistic conceptualisation of participation must therefore also be concerned with its results and concrete effects.

In the context of migration research, which unfolds in an extremely politicised, polarised and indeed hostile environment, the measure according to which results may be realistically assessed is hard to establish. Additionally, as mentioned, institutional pressure over academics, and particularly those - as in the case of the authors of these texts - who are in early and precarious stages of their career, makes it very difficult to avoid traditional forms of rendering accumulated knowledge such as scientific articles and events. Attempts at doing so might nonetheless occur, as exemplified in Bacon, Desille and Paté's work. Change might be less spectacular and take place at the individual level for research participants as captured in the 
notion of "empowerment" - a hope the reader shares regarding participants in Piemontese's research. Or, like in Augustová's text, visual products created in the course of the research may be in turn mobilised for advocacy and campaigning purposes.

In any case, the three texts of this section certainly encourage us to think through participation in a critical, reflexive and holistic manner, and to undertake further conceptual work around its many possibilities and potential limits. Ultimately, then, the texts expand our understanding of how participation can work in practice, but also of what it should tend towards in principle. They powerfully remind us of the social responsibility of researchers and inspire us to explore participatory methods as a means to ensure that our work gives space to researched groups, so that they may not only narrate their own experience and assert their political subjectivity, but also more actively set research agendas.

\section{References}

Albrecht, Y. (2016). Emotions in motion. How feelings are considered in the scope of migration sociological studies. Digithum, 18, 25-33.

Berger, J. (1972). Ways of seeing. London: Penguin Books.

Boulicaut, Y. (2013). There is no such thing as a candid shot. In G. Ganapathy-Doré \& M. Olinga (Eds.), Images of decolonization/images de La decolonisation. HAL Open Archive.

Cantat, C. (2016) The ideology of Europeanism and Europe's migrant other. International Socialism. Issue 152. https://isj.org.uk/the-ideology-of-europeanism-and-europes-migrant-other/

Chaudhary, Z. (2012). Afterimage of empire: Photography in nineteenth-century India. Minneapolis, MN: University of Minnesota Press.

Cornwall, A. (2006). Historical perspectives on participation in development. Commonwealth \& Comparative Politics, 44(1), 49-65.

De Genova, N. (2013). Spectacles of migrant 'illegality': the scene of exclusion, the obscene of inclusion. Ethnic and Racial Studies, 36(7), 1180-1198.

de Sousa Santos, B. (Ed.). (2008). Another knowledge is possible. Beyond northern epistemologies. London: Verso.

Deleuze, G. (1986). Foucault. Paris: Editions de Minuit.

Hall, B., \& Tandon, R. (2015). Are we killing knowledge systems? Knowledge, democracy, and transformations. Available online: http://www.politicsofevidence.ca/349/

Hall, S. (1992). Cultural studies and its theoretical legacies. In L. Grossberg, C. Nelson, \& P. A. Treichler (Eds.), Cultural studies (pp. 277-294). New York: Routledge.

Hickey, S., \& Mohan, G. (2005). Relocating participation within a radical politics of development. Development and Change, 36(2), 237-262.

Landau, P., \& Kaspin, D. (eds.) (2002). Images and empires visuality in colonial and postcolonial Africa. Berkeley: University of California Press

Maalki, L. (1996). Speechless emissaries: Refugees, humanitarianism, and dehistoricization. Cultural Anthropology, 11(3), 377-404.

Mirzoeff, N. (2008). Introduction to visual culture. New York: Routledge.

Mirzoeff, N. (2011). The right to look: A counterhistory of visuality. Durham, UK: Duke University Press.

Rajaram, P. K. (2016). Whose migration crisis? Intersections. East European Journal of Society and Politics, 2(4), 5-10. 
Rowell, L., \& Feldman, A. (2019). Knowledge democracy and action research. Educational Action Research, 27(1), 1-6.

Said, E. W. (1978). Orientalism. London: Penguin Books.

Stoddart, M. (2007). Ideology, hegemony, discourse: A critical review of theories of knowledge and power. Social Thought \& Research, 28, 191-225.

Open Access This chapter is licensed under the terms of the Creative Commons Attribution 4.0 International License (http://creativecommons.org/licenses/by/4.0/), which permits use, sharing, adaptation, distribution and reproduction in any medium or format, as long as you give appropriate credit to the original author(s) and the source, provide a link to the Creative Commons license and indicate if changes were made.

The images or other third party material in this chapter are included in the chapter's Creative Commons license, unless indicated otherwise in a credit line to the material. If material is not included in the chapter's Creative Commons license and your intended use is not permitted by statutory regulation or exceeds the permitted use, you will need to obtain permission directly from the copyright holder. 